\title{
First Record of Genus Sinorchestia (Crustacea: Amphipoda: Talitridae) from Korea
}

\author{
Min-Seop Kim, Dong-Ha Ahn and Gi-Sik Min* \\ Department of Biological Sciences, College of Natural Sciences, Inha University, \\ Incheon 402-751, Korea
}

\begin{abstract}
We present the first record of Sinorchestia sinensis (Chilton, 1925), the sandhopper, in Korea. This species was collected from the Baengnyeongdo Island of Korea. Descriptions of diagnostic characters of the species are provided on the text. A key to the species of Sinorchestia is provided.
\end{abstract}

Keywords: Talitridae, sandhopper, Sinorchestia sinensis, Korea

\section{INTRODUCTION}

Talitrid amphipods (Crustacea, Amphipoda) adapted to terrestrial habitats and include approximately 250 species in 52 genera worldwide (Serejo and Lowry, 2008). According to Bousfield (1984), the family Talitridae can be classified into four systematic-ecological units: palustral talitrids, beachfleas, sandhoppers and landhoppers. The genus Sinorchestia Miyamoto and Morino, 1999, is an endemic genus from the Northwestern Pacific region, belonging to the sandhoppers, which are characterized in terms of morphology by the peduncle article 3 of male antenna 2 with peduncular plate. Until now, 3 species of the genus have been recognized in Asia: Sinorchestia sinensis (Chilton, 1925), S. nipponensis (Morino, 1972) and S. taiwanensis Miyamoto and Morino, 1999.

S. sinensis was first reported as Talorchestia sinensis by Chilton (1925), and Miyamoto and Morino (1999) subsequently transfered this species to the genus Sinorchestia. This species was reported previously from China (Chilton, 1925), Japan (Morino, 1972) and Taiwan (Miyamoto and Morino, 1999). In this study, we report the first recording of this species in Korea.

Specimens instantly persevered in $95 \%$ ethyl alcohol were identified under a stereomicroscope (Olympus, SZX 12) and a light microscope (LEICA, DM 2500). Images of specimens were taken with a microscope digital camera (Moticam 2000), and produced with Helicon Focus ${ }^{\circledR}$ software (Helicon Soft, Ltd). All the materials used in this study were deposited in the Department of Biological Sciences, Inha University, South Korea.

\footnotetext{
*To whom correspondence should be addressed

Tel: 82-32-860-7692, Fax: 82-32-874-6737

E-mail: mingisik@inha.ac.kr
}

\section{SYSTEMATIC ACCOUNT}

Order Amphipoda Latreille, 1816

Family Talitridae Costa, 1857

${ }^{1}$ *Genus Sinorchestia Miyamoto and Morino, 1999

${ }^{2}$ * Sinorchestia sinensis (Chilton, 1925) (Figs. 1-4)

Talorchestia sinensis Chilton, 1925, p. 283, figs. a-d; Morino, 1972, p. 47, figs. 1-5.

Sinorchestia sinensis: Miyamoto and Morino, 1999, p. 169, figs. 11-14.

Material examined. 5 males and 8 females; Sagot beach $\left(37^{\circ}\right.$ $\left.56^{\prime} \mathrm{N}, 124^{\circ} 42^{\prime} \mathrm{E}\right)$, Baengnyeongdo Island, Baengnyeongmyeon, Ongjin-gun, Incheon, Korea; 18 Aug. 2009.

Description of male. Head (Figs. 1, 2A): body length 14.2 $\mathrm{mm}$, eyes round, width about 0.45 times as long as head diameter; buccal mass directed below head.

Antenna 1 (Figs. 1, 2A, C): antenna 1 not exceeding peduncle article 4 of antenna 2; peduncle articles 1-3 in length ratio $1: 0.8: 0.8$, with distal setae; flagellum with 5 articles.

Antenna 2 (Figs. 1, 2A, B, D): peduncle article 3-5 in length ratio $1: 2.6: 4.3$; peduncle article 3 with peduncular plate like a tomahawk, which with 10 spines on ventral margins; peduncle article 4 with a small protuberance on ventral margin; peduncle article 5 spinose along both margins; flagellum 21 articles, each article with short distal setae.

Upper lip (Fig. 2E): convex, with fine setae.

Mandible (Fig. 2G-I): left incisor 6 dentate, lacinia mobilis 5 dentate, molar triturative with 1 plumose seta; right incisor 6 dentate, lacinia mobilis furcate with numerous weak teeth.

Lower lip (Fig. 2F): concave, with fine setae, inner plate absent.

Maxilla 1 (Fig. 2J, K): inner plate having 2 large plumose setae on apical margin; outer plate with 9 saw-like spines

$1 *$ 주걱도약옆새 우속 (신칭), ${ }^{2}$ *중국주걱도약옆새우 (신칭) 


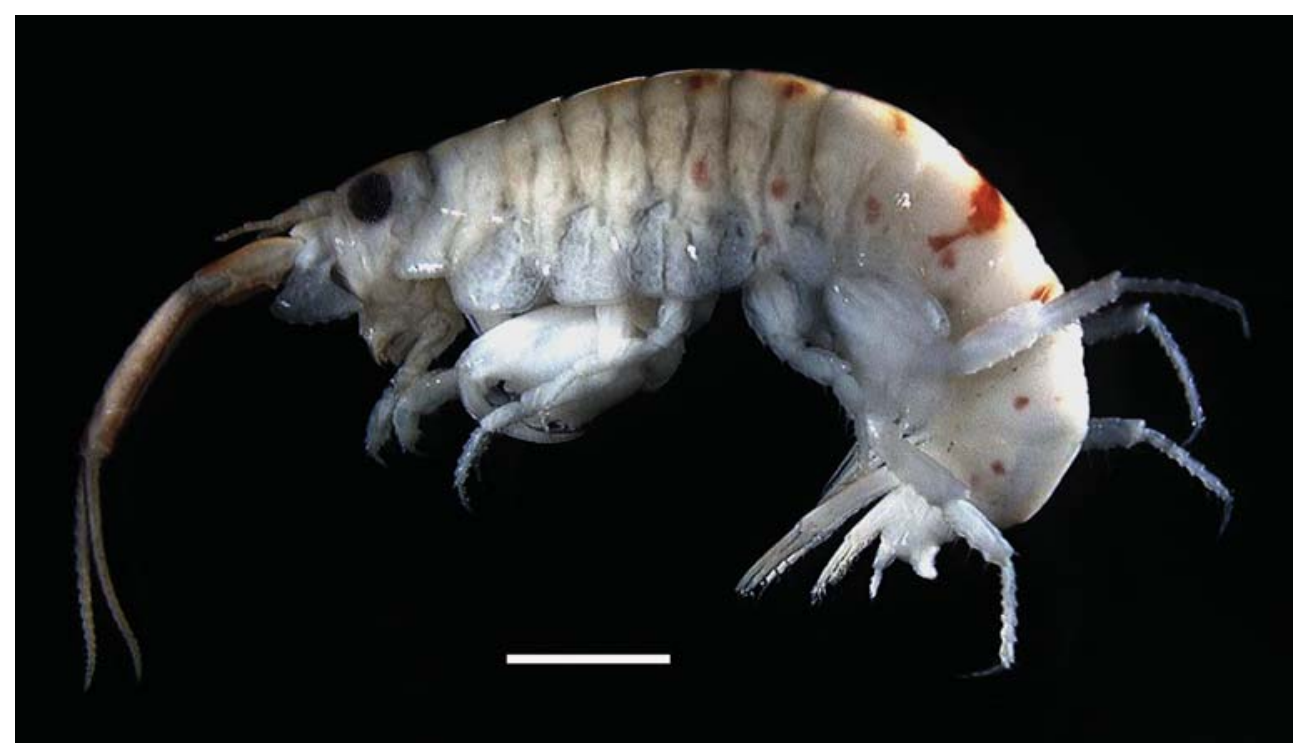

Fig. 1. Sinorchestia sinensis (Chilton, 1925): male (lateral view), $14.2 \mathrm{~mm}$. Scale bar=2 mm.

and rudimentary palp on apical and outer margins.

Maxilla 2 (Fig. 2L): inner plate with 1 large plumose seta on medial margin, with an article setae; outer plate bearing distal setae.

Maxilliped (Fig. 2M, N): inner plate having 3 blunt distal spines; palp article 4 projected beyond article 3 , ventral surface with dense spines.

Gnathopod 1 (Fig. 2O, P): coxal plate 1 triangular in shape, with many fine setae on posterior margin; basis with numerous spines on anterior margin, posterior margin weakly curved, with 3 spines; merus with 10 spines on posterior margin; carpus with 10 spines and tumescent hump on posterior margin; propodus approximately 0.65 times as long as carpus, posterior margin spinose, with tumescent hump, the longest spine approximately 2 times as long as hump diameter, dorsal margin with 4 tufts of 2-3 short spines, palmar margin with several short spines on outer surface and with 1 long spine on inner margin; dactyl nail slightly longer than dactyl base.

Gnathopod 2 (Fig. 2Q-S): coxal plate 2 with numerous fine setae on ventral margin, posterior margin with very small cusp; anterior margin of the basis marginally bare, while posterior margin bearing 7 short spines; merus slightly shorter than ischium, with several short spines on posterior margin; propodus oval in shape, with several short spines on posterior margin and 2 strong spines on posterior corner, palmar having 2 protrusions, one situated near the hinge of dactyl, small and triangular in shape, while the other semicircular in shape, with numerous spines; dactyl exceeding palmar margin, posterior margin of dactyl with small pro- trusion and numerous short spines.

Pereopod 3-4 (Fig. 3A-F): pereopod 3 longer than pereopod 4 ; coxal plate 3 with many fine setae on ventral margin, posterior margin with cusp; basis almost parallel-sided, anterior margin with several short spines, posterior margin with 5 spines; merus to propodus in length ratio $1: 0.77$ : 0.91 , both anterior and posterior margins with several tufts of 2-3 spines; dactyl with 1 stiff seta at hinge of nail; pereopod 4 similar to pereopod 3, except for a thickened dactyl base and pinched posteriorly.

Pereopods 5-7 (Fig. 3G-P): anterior lobe of coxal plate 5 wider than posterior one, while coxal plate 6 anterior lobe very small and coxal plate 7 non-lobate; basis with a row of several fine setae and spines on posterior and anterior margins; merus to propodus with several spines along both margins; dactylus with 1 stiff seta near hinge of nail.

Coxal gills (Figs. 2R, 3B, F, H, K): gill of gnathopod 2 wavy; gills of pereopods 3,4 and 6 hooked in middle, narrowing distally; gill of pereopod 5 oval in shape, and broadened distally.

Epimeral plates (Fig. 3Q-S): ventral margins of plates without marginal spines, posterior margins with 2-3 setae, while posterodistal corner acute.

Pleopods 1-3 (Fig. 4A-D): pleopods subequal in length, peduncles of pleopods with 2 retinaculae distally, both rami with about 10-12 articles, armed with plumose setae; pleopod 1 with 4 spines on proximal margin of peduncle; peduncle of pleopod 2 with 12 spines on outer margin except distal parts, peduncle of pleopod 3 with 11 and 3 spines on outer margin and dorsal surface. 

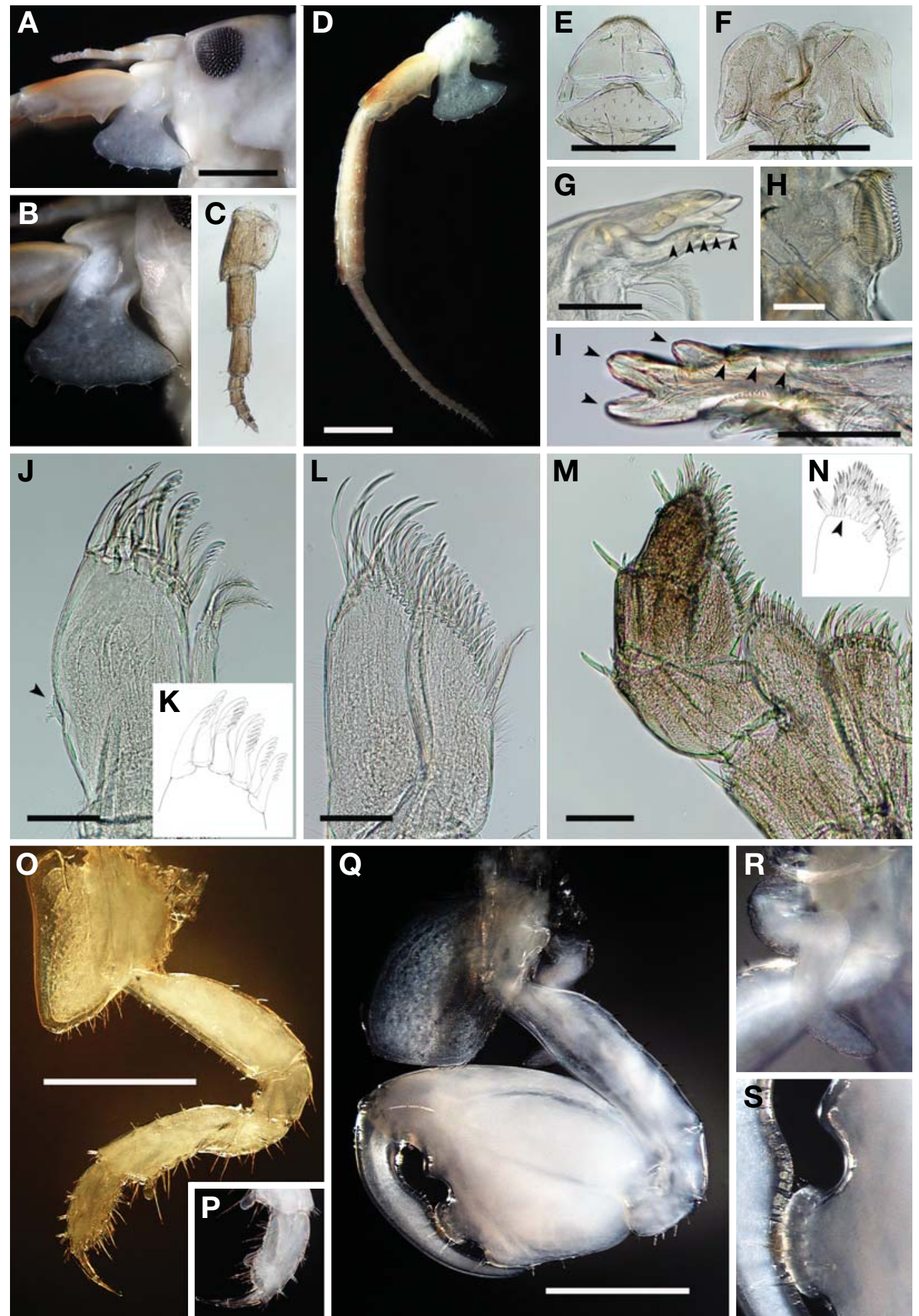

Fig. 2. Sinorchestia sinensis (Chilton, 1925), male, $14.2 \mathrm{~mm}$ : A, head; $B$, peduncular plate of antenna 2; C, antenna 1 ; D, antenna 2; E, upper lip; F, lower lip; G, incisor of left mandible, arrowheads indicate lacinia mobilis; $H$, molar of left mandible; $I$, incisor of right mandible, arrowheads shows incisor dentate; J, maxilla 1 , arrowhead indicate rudimentary palp; $\mathrm{K}$, saw-like spines of maxilla 1 ; $\mathrm{L}$, maxilla $2 ; \mathrm{M}$, maxilliped; $\mathrm{N}$, article 3 of maxilliped, arrowhead indicate article 4 ; O, gnathopod 1 ; $\mathrm{P}$, inner margin of propodus in gnathopod $1 ; \mathrm{Q}$, gnathopod 2; R, gill of gnathopod 2; S, palm of gnathopod 2. Scale bars=1 mm $(A, D, O, Q), 0.5 \mathrm{~mm}(E, F), 100$ $\mu \mathrm{m}(\mathrm{G}-\mathrm{J}, \mathrm{L}, \mathrm{M})$. 

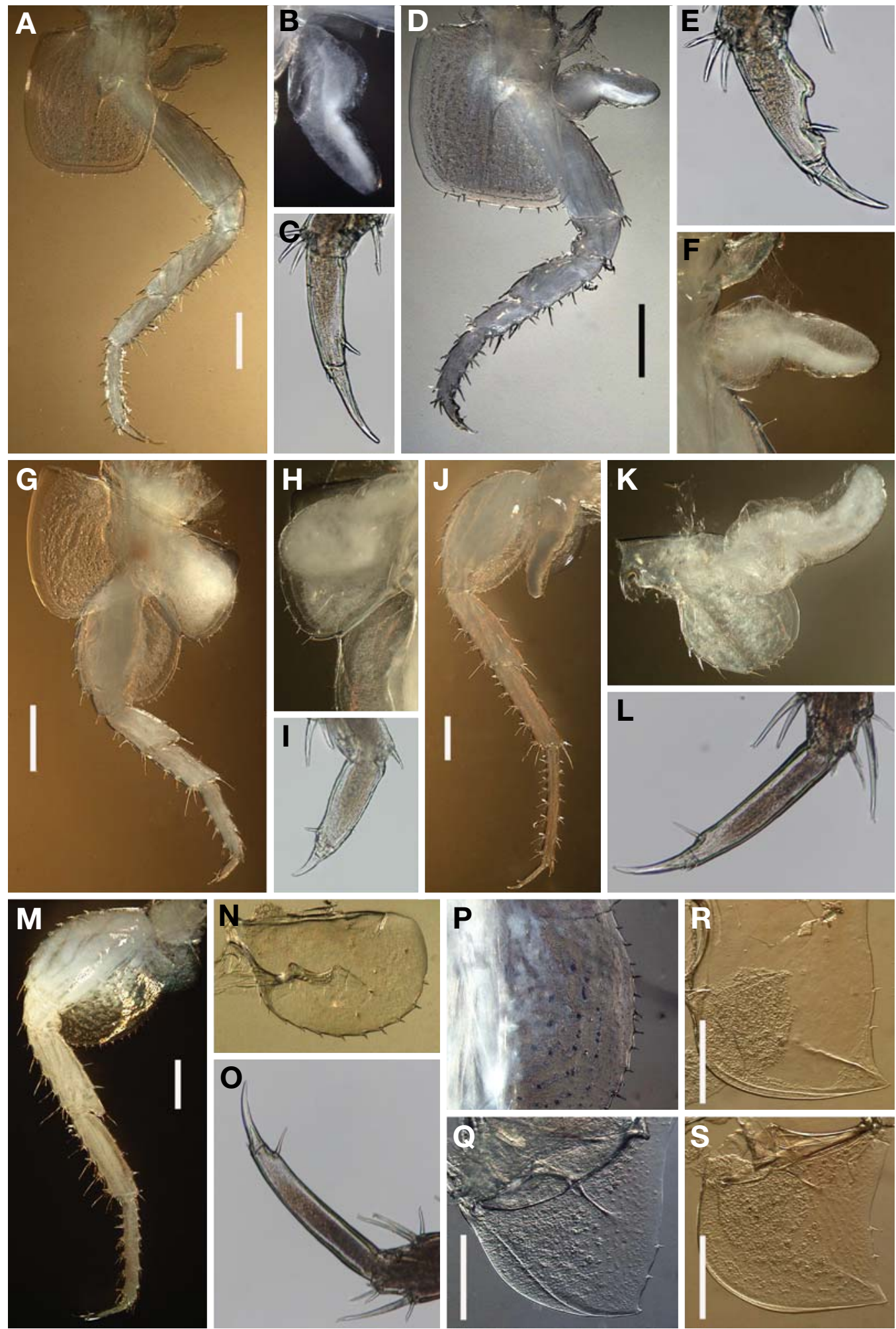

Fig. 3. Sinorchestia sinensis (Chilton, 1925), male, $14.2 \mathrm{~mm}$ : A, pereopod 3; B, gill of pereopod 3; C, dactylus of pereopod 3; D, pereopod $4 ; E$, dactylus of pereopod $4 ; F$, gill of pereopod $4 ; G$, pereopod $5 ; \mathrm{H}$, gill of pereopod 5 ; I, dactylus of pereopod 5 ; J, pereopod $6 ; \mathrm{K}$, gill of pereopod $6 ; \mathrm{L}$, dactylus of pereopod $6 ; \mathrm{M}$, pereopod 7; N, coxal plate of pereopod 7; O, dactylus of pereopod 7; P, posterior margin of basis in pereopod 7; $Q$, epimeral plate 1 ; R, epimeral plate 2; S, epimeral plate 3. Scale bars $=0.5 \mathrm{~mm}(A, D, G$, J, M, Q-S). 

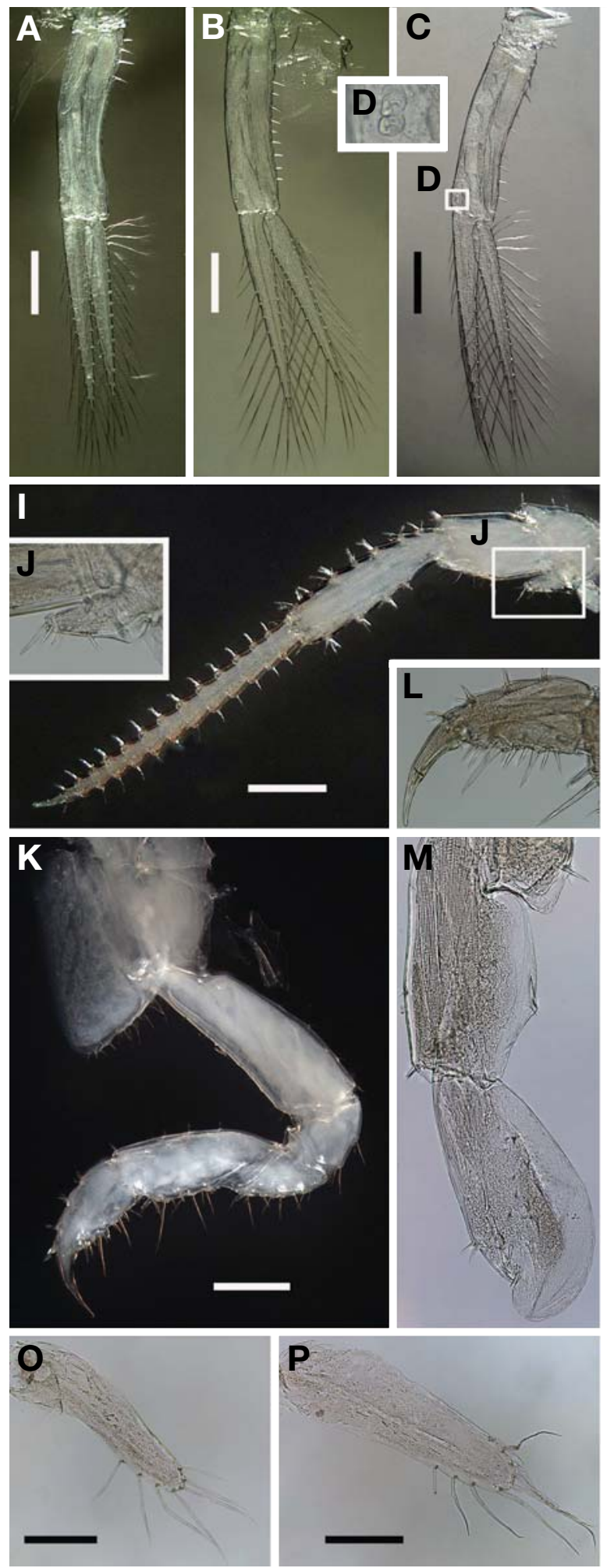
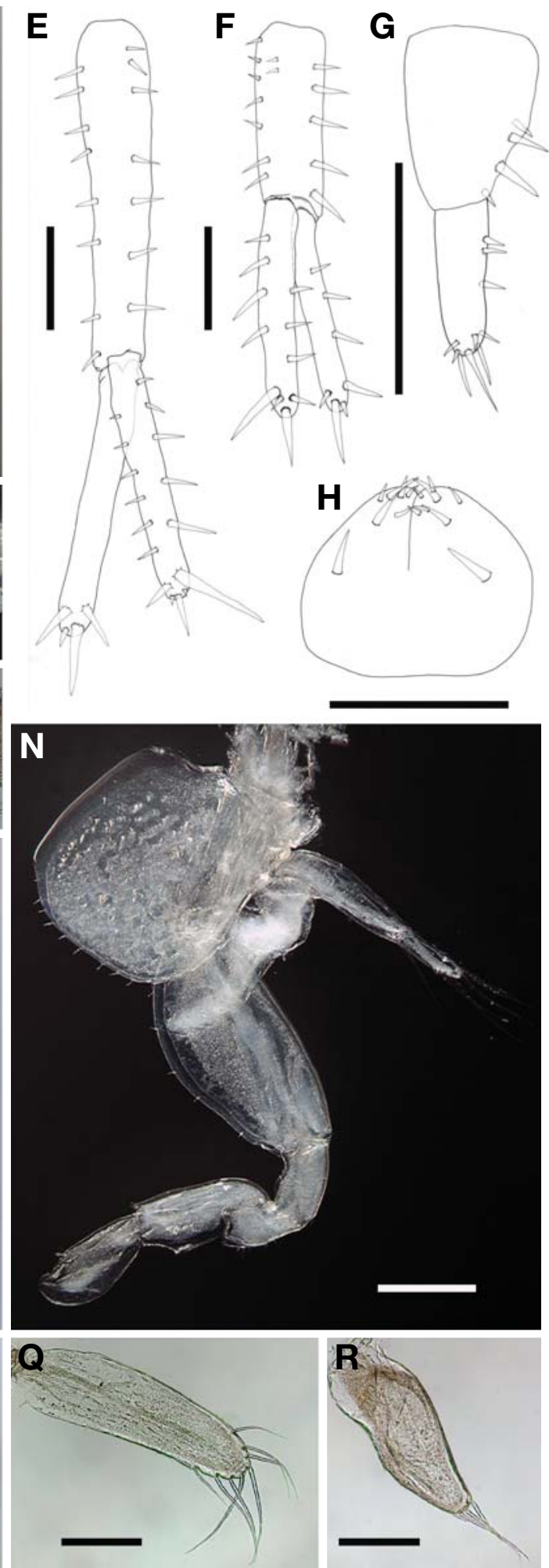

Fig. 4. Sinorchestia sinensis (Chilton, 1925), male, $14.2 \mathrm{~mm}$ : A, pleopod 1; B, pleopod 2; C, pleopod 3; D, retinacula of pleopod 3; $\mathrm{E}$, uropod $1 ; \mathrm{F}$, uropod $2 ; \mathrm{G}$, uropod $3 ; \mathrm{H}$, telson; female, $10.5 \mathrm{~mm}$ : I, antenna $2 ; \mathrm{J}$, peduncular plate of antenna $2 ; \mathrm{K}$, gnathopod $1 ; \mathrm{L}$, propodus of gnathopod $1 ; \mathrm{M}$, propodus of gnathopod 2; N, gnathopod 2; O, oostegite of gnathopod 2; P, oostegite of pereopod 3; Q, oostegite of pereopod $4 ; R$, oostegite of pereopod 5 . Scale bars $=0.3 \mathrm{~mm}(\mathrm{~A}-\mathrm{C}, \mathrm{E}-\mathrm{I}, \mathrm{K}, \mathrm{N}, \mathrm{O}-\mathrm{R})$. 
Uropod 1 (Fig. 4E): peduncle approximately 1.25 times as long as outer ramus, with 8 and 7 spines on outer and inner margins, respectively; outer ramus slightly longer than inner ramus, marginally bare, with 4 distal spines; inner ramus with 6, 5 and 5 spines on inner, outer and distal margins, respectively.

Uropod 2 (Fig. 4F): peduncle approximately 0.76 times as long as outer ramus, with 7 and 4 spines on outer and inner margins, respectively, bearing 2 basofacial spines; inner ramus slightly shorter than outer ramus, with 3 marginal and 4 distal spines, respectively, outer ramus with 3 inner marginal and 4 outer marginal, respectively, 4 distal spines.

Uropod 3 (Fig. 4G): peduncle with 3 lateral and 1 distal spines, ramus approximately 0.85 times as long as peduncle, bearing 3 spines on dorsal margin, bearing 3 long and 4 short spines on distal margin.

Telson (Fig. 4H): apically notched, with 6-7 distal spines and 1 sublateral spine on each lobe.

Description of female. General appearance similar to male. Differences as follows:

Antenna 2 (Fig. 4I, J): peduncular plate smaller than that of male, and extended forward; peduncle article 3-5 in length ratio $1: 1.7: 2.9$, peduncle article 5 with short spines along both margins; flagellum 14 articles.

Gnathopod 1 (Fig. 4K, L): merus, carpus and propodus with many spines and without tumescent humps on posterior margin; propodus triangular in shape, palmar margin very short; dactylus approximately 0.9 times as long as propodus.

Gnathopod 2 (Fig. 4M, N): coxal plate with very small cusp on posterior margin; basis anteriorly expanded, anterior margin with 5 minute spines, posterior margin straight, marginally bare; merus with transparent lobe on posterodistal corner, posterior margin with a few spines; carpus with transparent lobe on posterior margin, with 1 minute spine; propodus extended posterodistally, with a few spines on lateral surface; dactylus nail smooth.

Oostegites (Fig. 4N-R): oostegites 2-4 elongate, with 7-9 setae, oostegite 5 triangular, with 4 setae on distal margin.

Distribution. China, Japan, Taiwan and Korea (Baengnyeongdo Island).

Remarks. S. sinensis resembles $S$. taiwanensis in following characteristics: (1) peduncle article 3 of antenna 2 with triangular plate; (2) epimeral plate 1 marginally bare on ventral margin; and (3) outer ramus of uropod 1 without marginal spines. However two species presented with following dissimilarities: in male, merus of gnathopod 2 does not have tumescent hump on posterior margin while merus of gnathopod 2 of $S$. taiwanensis has.

S. sinensis are distributed in China (Chilton, 1925), Japan
(Morino, 1972) and Taiwan (Miyamoto and Morino, 1999).

Korean S. sinensis coincides well with the description of specimens in other countries, however they differ from Chinese specimens in that the palm of male gnathopod 2 had a small and triangular protrusion located near the hinge of dactyl. Three species of Sinorchestia can be distinguished by following key.

\section{Key to the species of Sinorchestia}

1. Peduncle article 3 of antenna 2 with peduncular plate; epimeral plate 1 without marginal setae on ventral margin; outer ramus of uropod 1 marginally bare $. . . \ldots \ldots \ldots \ldots \ldots . . . \cdots 2$

- Peduncle article 3 of antenna 2 with peduncular plate; epimeral plate 1 bearing short setae on ventral margin; outer ramus of uropod 1 with marginal spines

S. nipponensis (Morino, 1972)

2. Gnathopod 2 of male, merus with small tumescent hump on posterior margin

S. taiwanensis Miyamoto and Morino, 1999

- Gnathopod 2 of male, merus without tumescent hump on posterior margin ….............. S. sinensis (Chilton, 1925)

\section{ACKNOWLEDGEMENTS}

This work was supported by grant of the Korea Healthcare technology R\&D Project, Ministry for Health, Welfare \& Family Affairs, Republic of Korea (A090931).

\section{REFERENCES}

Bousfield, E.L., 1984. Recent advances in the systematics and biogeography of landhoppers (Amphipoda: Talitridae) of the Indo-pacific region. Natl. Mus. Nat. Sci., 72: 171-210.

Chilton, C., 1925. On a species of Talorchestia. China J. Sci. Art., 3: 283-284

Miyamoto, H. and H. Morino, 1999. Taxonomic studies on the Talitridae (Crustacea, Amphipoda) from Taiwan. Publ. Seto Mar. Biol. Lab., 38(5/6): 169-200.

Morino, H., 1972. Studies on the Talitridae (Amphipoda, Crustacea) in Japan. 1. Taxonomy of Talorchestia and Orchestoidea. Publ. Seto Mar. Biol. Lab., 21(1): 43-65.

Serejo, C.S. and J.K. Lowry, 2008. The coastal Talitridae (Amphipoda: Talitroidea) of Southern and Western Australia, with comments on Platorchestia platensis (Kroyer, 1845). Rec. Aust. Mus., 60(2): 161-206. 